\title{
Bereavement in Early Life and Later Childhood Overweight
}

\author{
Jiong Li ${ }^{a} \quad$ Jørn Olsen ${ }^{a, b} \quad$ Mogens Vestergaard ${ }^{c, d} \quad$ Carsten Obel $^{d}$ \\ Jennifer L. Baker ${ }^{\mathrm{e}}$ Thorkild I.A. Sørensen ${ }^{\mathrm{e}}$
}

\begin{abstract}
a Section for Epidemiology, Department of Public Health, Aarhus University, Aarhus, Denmark, ${ }^{b}$ Department of Epidemiology, School of Public Health, University of California, Los Angeles, CA, USA, 'Research Unit for General Practice, Aarhus University, Aarhus, dSection of General Practice, Department of Public Health, Aarhus University, Aarhus, ${ }^{\mathrm{e}}$ Institute of Preventive Medicine, Copenhagen University Hospital, Copenhagen, Denmark
\end{abstract}

\section{Key Words}

Stress $\cdot$ Bereavement $\cdot$ Overweight $\cdot$ Childhood obesity $\cdot$ Body mass index

\section{Abstract}

Objective: The rise in the occurrence of childhood obesity during the last decades in many populations indicates an important role of environmental exposures, which may operate very early in life. We aimed to examine the association between bereavement during the first 6 years of life, as a stress indicator, and subsequent risk of overweight in school-aged children. Methods: We followed 46,401 singletons born in Denmark who underwent annual health examinations at 7-13 years of age in school of Copenhagen. A total of 492 children experienced bereavement by death of a parent during the first 6 years of life. We compared BMI levels, changes in BMI, and the prevalence of overweight at 7-13 years of age between bereaved and non-bereaved children. Results: Between bereaved children and non-bereaved children, there were no differences in average BMI levels at any age or changes in BMI at 7-13 years of age. Bereavement during the first 6 years of life was not associated with an increased risk of overweight at 7-13 years of age. Conclusion: This study did not support that stress induced by bereavement during the first 6 years of life has significant influence on overweight in later childhood. 
Li et al.: Bereavement in Early Life and Later Childhood Overweight

\section{Introduction}

One out of 10 school-aged children worldwide is overweight or obese, which decreases quality of life and increases the risk of several chronic diseases [1, 2]. The rise in the occurrence of childhood obesity during the last decades in many populations indicates an important role of environmental exposures, which may operate very early in life $[3,4]$. However, little is known about the etiology [5, 6]. Breastfeeding has been associated with a lower risk [7, 8], while over- or undernutrition in infancy followed by overnutrition has been associated with increased risk of childhood or adulthood obesity [9]. Several other variables related to birth as well as to behavioral and social factors have been suggested to be associated with the risk of childhood obesity, but the evidence remains uncertain [10], providing limited clues for effective prevention $[5,6]$.

Animal studies have demonstrated that stress during the early period of life is associated with epigenetic and metabolic changes [11], which may have a programming effect on the development of overweight and obesity in the future [12-14]. Early life stress in humans can lead to pathophysiological changes in the neuroendocrine systems [15], psychological symptoms, and behavioral changes in children [16], which could influence the risk of overweight or obesity [17]. Maternal postpartum distress has been suggested to affect their children and increase the risk of childhood obesity [18-20].

The death of a parent is classified as one of the most stressful life events that a child can experience [21,22], and loss of a father during the first postnatal years may stress mothers and influence feeding behaviors or child rearing $[1,19]$. Bereavement during the early life period may also influence children via a direct metabolic influence of stress and behavioral mechanisms $[17,19]$. In this study, we examined whether bereavement during the first 6 years of life was associated with an increased risk of overweight in school children at 7-13 years of age.

\section{Material and Methods}

Study Design and Population

This population-based cohort study was based on linkage of the Danish Civil Registration System [23], the Danish Medical Birth Register [24], the Integrated Database for Longitudinal Labor Market Research (IDA) [25], and the Copenhagen School Health Records Register (CSHRR) [26]. All live born children and new residents in Denmark since 1969 have been assigned a unique civil personal registration (CPR) number, allowing accurate linkage of data between registries [27]. Information on demographic, vital statistics, and family relationships is retrievable from the Danish Civil Registration System [23]. Thus, within this system, it is possible in a single study to follow all residents for decades and link data at an individual level on demographic, vital status, social and economic conditions, and health information [27].

We first identified all singletons born in Denmark from 1973 to1989 through the Danish Civil Registration System [24]. By using their personal identification number and links to family members, we identified their parents, for whom information on the date and cause of death could also be retrieved [24]. Children were subsequently linked to the CSHRR [26], which holds data on health examinations of children enrolled in public or private schools in the municipality of Copenhagen. A total of 46,401 singletons who had ever resided in Copenhagen and had records in CSHRR were included in the study. Children who had lost a parent during the first 6 years of life were categorized as exposed. The remaining children were in the unexposed cohort.

Sensitivity to stress exposure is expected to vary with the age of the child and the type of bereavement [28]. The exposure was stratified by timing of exposure at different years of age (all, $0-2$, 3-4, 5-6 years), and exposure was further categorized into two groups (loss of a father or loss of a mother). Finally, the exposure was categorized by the causes of death into two groups: unexpected death (unexpected causes, ICD8 codes 7950-7959, ICD 10 codes R95-R97, motor vehicle accidents, ICD8 
Table 1. Exposure to bereavement by death of a parent at each age

\begin{tabular}{llll}
\hline Age of the child & Parents & Mother & Father \\
\hline 1st year & 49 & 12 & 37 \\
2nd year & 60 & 12 & 48 \\
3rd year & 81 & 21 & 61 \\
4th year & 90 & 22 & 68 \\
5th year & 100 & 21 & 79 \\
6th year & 112 & 26 & 86 \\
All ages (1-6 years) & 492 & 114 & 379 \\
\hline
\end{tabular}

codes 8100-8230, ICD10 codes V01-V89, suicide, ICD8 codes 950-959, ICD10 codes X60-X84, other accidents and violence, ICD8 codes 800-807, 825-949, 960-999, ICD10 codes V90-V99, W00-X59, X85-Y89) and death by other causes.

The definition of childhood overweight at specific ages $(7,8,9,10,11,12$, and 13 years) was based on the International Obesity Task Force gender- and age-specific BMI references [29]. The measurements of weight and height were retrieved from the CSHRR [26]. BMI was calculated as weight $(\mathrm{kg}) / \mathrm{height}(\mathrm{m})^{2}$ at a given age. School doctors and nurses recorded heights to the nearest half-centimeter and weights to the nearest $100 \mathrm{~g}$. When the data were computerized, the data entry program applied a series of range and consistency checks to minimize coding errors. Furthermore, as there were longitudinal measurements of the children, their growth curves were plotted and examined for unusual values. These values were verified in the original records which are stored in the municipal archive [26].

Information on birth outcomes, such as birth weight and gestational age, was obtained from the Danish Medical Birth Register [24], which was established in 1973. Information on socioeconomic factors (maternal age, maternal residential place, maternal education, maternal income, and maternal cohabitation status) was obtained from the Integrated Database for Longitudinal Labour Market Research (IDA), and these data were available from 1980 and onwards [25].

\section{Statistical Analysis}

The data were analyzed in SAS (version 9.1) and Stata (version 12). Chi-square ( $\chi^{2}$ ) test was used to determine whether the levels of overweight at each age $(7,8,9,10,11,12,13$ years) were similar between the exposed and the unexposed. The differences in mean BMI values between the exposed and unexposed groups at each age were analyzed using General Linear Model (GLM). The odds ratios (ORs) for overweight at each age between the exposed and the unexposed were analyzed using logistic regression. We adjusted for the following potential confounding variables: gender (male, female), birth year, (gestational age $(<37, \geq 37$ weeks, unknown), birth weight $(<3,000,3,000-3,350,3,350-3,700$, $\geq 3,700$ g, unknown), and maternal age $(<27,27-30, \geq 31$ years $)$. Maternal characteristics of school education (0-9 years, 10-11 years, $\geq 12$ years, unknown), income (lowest quartile, 2 nd quartile, 3rd quartile, highest quartile in the calendar year, unknown), and marital status (yes, no, unknown) were included.

As maternal characteristics of school education, income, and marital status were available only for the period 1980-1989, we imputed the missing values for the period 1973-1979 using a multiple imputation technique [30].

In order to take into account repeated BMI measurements at different ages, we performed hierarchical linear analysis using SAS Proc Mixed procedure [31].

Ethics

The Danish Data Protection Agency approved the study (J.nr. 2008-41-2555, J.nr. 2008-41-2680). The study was based on secondary data, and no individuals were approached, nor did we have access to any personal identification of the participants. The study was thus exempted from obtaining written consent according to Danish law. 
Table 2. Baseline characteristics of the study population

\begin{tabular}{|c|c|c|c|c|c|}
\hline \multirow[t]{2}{*}{ Variables } & \multicolumn{2}{|c|}{$\begin{array}{l}\text { Exposed cohort } \\
(n=492)\end{array}$} & \multicolumn{2}{|c|}{$\begin{array}{l}\text { Unexposed cohort } \\
(\mathrm{n}=45,909)\end{array}$} & \multirow[t]{2}{*}{ P value } \\
\hline & no. & $\%$ & no. & $\%$ & \\
\hline Gender & & & & & 0.60 \\
\hline Boys & 245 & 50 & 23,404 & 51 & \\
\hline Girls & 247 & 50 & 22,505 & 49 & \\
\hline Preterm birth & & & & & 0.43 \\
\hline Yes & 27 & 4 & 2,040 & 4 & \\
\hline No & 423 & 86 & 40,273 & 88 & \\
\hline Unknown & 42 & 9 & 3,596 & 8 & \\
\hline Birth year & & & & & 0.96 \\
\hline 1973-1978 & 184 & 37 & 17,104 & 37 & \\
\hline 1979-1983 & 132 & 27 & 12,113 & 26 & \\
\hline 1984-1989 & 176 & 36 & 16,692 & 36 & \\
\hline Maternal age, years & & & & & $<0.01$ \\
\hline$\leq 23$ & 106 & 22 & 10,540 & 23 & \\
\hline $24-26$ & 99 & 20 & 11,129 & 24 & \\
\hline $27-30$ & 118 & 24 & 11,995 & 26 & \\
\hline$>30$ & 169 & 34 & 12,245 & 27 & \\
\hline Birth weight, g & & & & & $<0.01$ \\
\hline$<3,000$ & 130 & 26 & 9,300 & 20 & \\
\hline $3,000-3,350$ & 122 & 25 & 11,324 & 25 & \\
\hline $3,350-3,700$ & 107 & 22 & 11,377 & 25 & \\
\hline$>3,700$ & 101 & 21 & 11,966 & 26 & \\
\hline Unknown & 32 & 7 & 1,940 & 4 & \\
\hline Maternal education & & & & & 0.04 \\
\hline Primary & 124 & 25 & 10,013 & 22 & \\
\hline Secondary & 41 & 8 & 4,001 & 9 & \\
\hline High & 55 & 11 & 7,059 & 15 & \\
\hline Unknown & 272 & 55 & 24,836 & 54 & \\
\hline Maternal income & & & & & 0.18 \\
\hline$\leq 0$ & 32 & 7 & 2,130 & 5 & \\
\hline Low $(1 / 3)$ & 50 & 10 & 4,399 & 10 & \\
\hline Middle (1/3) & 59 & 12 & 6,763 & 15 & \\
\hline High $(1 / 3)$ & 106 & 22 & 9,975 & 22 & \\
\hline Unknown & 245 & 50 & 22,642 & 49 & \\
\hline Marital status & & & & & 0.81 \\
\hline Single & 121 & 25 & 11,838 & 26 & \\
\hline Cohabitation & 127 & 26 & 11,469 & 25 & \\
\hline Unknown & 244 & 50 & 22,602 & 49 & \\
\hline
\end{tabular}

*The $p$ value is for the difference between the exposed and the unexposed. 
Table 3. Mean BMI, differences in means of BMI, prevalence of overweight, and OR of overweight at age 7 according to type of relative and timing of exposure

\begin{tabular}{|c|c|c|c|c|c|c|}
\hline Exposure & $\begin{array}{l}\text { Number of } \\
\text { children }\end{array}$ & Mean BMI & $\begin{array}{l}\text { Differences in means o } \\
\text { BMI }^{*}\end{array}$ & $\begin{array}{l}\text { f Overweight } \\
\text { cases }\end{array}$ & $\begin{array}{l}\text { Overweight } \\
\text { prevalence }\end{array}$ & OR of overweight ${ }^{\dagger}$ \\
\hline \multicolumn{7}{|l|}{ Death of a parent } \\
\hline No & 33,882 & $15.92 \pm 1.68$ & Ref. & 3,744 & 11.0 & Ref. \\
\hline Yes - all 6 years & 375 & $15.85 \pm 1.74$ & $-0.03(-0.20$ to 0.14$)$ & 38 & 10.1 & $0.93(0.66-1.30)$ \\
\hline Yes - 1-2 years & 81 & $15.79 \pm 1.75$ & $-0.12(-0.49$ to 0.24$)$ & 7 & 8.6 & $0.74(0.34-1.61)$ \\
\hline Yes - 3-4 years & 120 & $15.78 \pm 1.61$ & $-0.10(-0.39,0.19)$ & 10 & 7.7 & $0.70(0.36-1.36)$ \\
\hline Yes - 5-6 years & 164 & $15.95 \pm 1.83$ & $0.07(-0.18,0.32)$ & 21 & 12.8 & $1.23(0.67-1.96)$ \\
\hline \multicolumn{7}{|l|}{ Death of a father } \\
\hline No & 33,966 & $15.93 \pm 1.69$ & Ref. & 3,753 & 11.1 & Ref. \\
\hline Yes - all 6 years & 291 & $15.83 \pm 1.67$ & $-0.08(-0.27$ to 0.11$)$ & 29 & 10.0 & $0.89(0.60-1.31)$ \\
\hline Yes - 1-2 years & 64 & $15.78 \pm 1.65$ & $-0.15(-0.56$ to 0.26$)$ & 5 & 7.8 & $0.65(0.26-1.63)$ \\
\hline Yes - 3-4 years & 98 & $15.74 \pm 1.37$ & $-0.17(-0.49$ to 0.17$)$ & 7 & 7.1 & $0.63(0.29-1.36)$ \\
\hline Yes - 5-6 years & 129 & $15.91 \pm 1.88$ & $0.02(-0.27$ to 0.30$)$ & 10 & 13.2 & $1.23(0.73-2.06)$ \\
\hline \multicolumn{7}{|l|}{ Death of a mother } \\
\hline No & 34,172 & $15.92 \pm 1.67$ & Ref. & 3,773 & 11.0 & Ref. \\
\hline Yes - all 6 years & 85 & $15.95 \pm 1.69$ & $0.13(-0.22$ to 0.49$)$ & 9 & 10.6 & $1.06(0.53-2.14)$ \\
\hline Yes - 1-2 years & 17 & $15.83 \pm 2.13$ & $-0.02(-0.81$ to 0.77$)$ & 2 & 11.8 & $1.02(0.25-5.04)$ \\
\hline Yes - 3-4 years & 33 & $15.87 \pm 2.19$ & $0.07(-0.50$ to 0.63$)$ & 3 & 9.1 & $0.88(0.26-2.92)$ \\
\hline Yes - 5-6 years & 35 & $16.08 \pm 1.67$ & $0.27(-0.28$ to 0.83$)$ & 4 & 11.4 & $1.20(0.42-3.46)$ \\
\hline
\end{tabular}

\section{Results}

We identified 492 children who experienced bereavement during the first 6 years of life (table 1). The exposed and unexposed children were comparable for most baseline characteristics. The exceptions were low birth weight, low maternal education, and high maternal age, which were slightly overrepresented in the exposed group (table 2).

The numbers of children who had measurements of BMI were 34,257 at age 7, 28,027 at age $8,18,837$ at age $9,14,420$ at age 10,11,959 at age 11,11,171 at age 12, and 9,532 at age 13.

Table 3 shows that there were no differences in mean BMI values and in the prevalence of overweight between the exposed and unexposed groups at age 7. Compared to children in the nonexposed group, the exposed children did not show significant differences in the means of BMI or in the odds of being overweight after adjusting for potential confounders. Similar results were observed for age 13 (table 4). Results from the other ages were also similar, and data are not shown.

Table 5 presents the difference in BMI between the exposed and the unexposed when repeated measurements at each age were taken into account, and the analyses were based on 13,068 children who had at least 4 measurements between 7 and 13 years of age. The adjusted overall difference in BMI between the exposed and the unexposed was -0.01 (95\% confidence interval (CI) -0.40 to 0.38 ). 
Table 4. Mean BMI, differences in means of BMI, Prevalence of overweight, and OR of overweight at age 13 according to type of relative and timing of exposure

\begin{tabular}{|c|c|c|c|c|c|c|}
\hline Exposure & $\begin{array}{l}\text { Number of } \\
\text { children }\end{array}$ & Mean BMI & $\begin{array}{l}\text { Differences in means o } \\
\text { BMI }^{*}\end{array}$ & $\begin{array}{l}\text { fOverweight } \\
\text { cases }\end{array}$ & $\begin{array}{l}\text { Overweight } \\
\text { prevalence }\end{array}$ & OR of overweight ${ }^{\dagger}$ \\
\hline \multicolumn{7}{|l|}{ Death of a parent } \\
\hline No & 9,420 & $19.37 \pm 3.23$ & Ref. & 1,622 & 17.2 & Ref. \\
\hline Yes - all 6 years & 112 & $19.57 \pm 3.34$ & $0.15(-0.45$ to 0.75$)$ & 20 & 17.9 & $1.01(0.62-1.65)$ \\
\hline Yes - 1-2 years & 25 & $20.89 \pm 3.83$ & 1.41 ( 0.15 to 2.67$)$ & 6 & 24.0 & $1.44(0.56-3.69)$ \\
\hline Yes - 3-4 years & 34 & $19.36 \pm 3.25$ & $-0.04(-1.13$ to 1.04$)$ & 6 & 17.7 & $1.03(0.42-2.51)$ \\
\hline Yes - 5-6 years & 53 & $19.07 \pm 3.05$ & $-0.32(-1.19$ to 0.54$)$ & 8 & 15.1 & $0.82(0.38-1.75)$ \\
\hline \multicolumn{7}{|l|}{ Death of a father } \\
\hline No & 9,455 & $19.37 \pm 3.25$ & Ref. & 1,625 & 17.2 & Ref. \\
\hline Yes - all 6 years & 77 & $19.88 \pm 3.76$ & $0.40(-0.32$ to 1.12$)$ & 17 & 22.1 & $1.27(0.73-2.20)$ \\
\hline Yes - 1-2 years & 18 & $21.35 \pm 3.76$ & $1.80(0.31$ to 3.29$)$ & 5 & 28.8 & $1.63(0.57-4.67)$ \\
\hline Yes - 3-4 years & 21 & $19.75 \pm 3.33$ & $0.25(-1.13$ to 1.63$)$ & 5 & 23.4 & $1.46(0.53-4.04)$ \\
\hline Yes - 5-6 years & 38 & $19.23 \pm 3.35$ & $-0.18(-1.20$ to 0.85$)$ & 7 & 18.4 & $1.02(0.44-2.33)$ \\
\hline \multicolumn{7}{|l|}{ Death of a mother } \\
\hline No & 9,496 & $19.38 \pm 3.25$ & Ref. & 1,639 & 17.2 & Ref. \\
\hline Yes - all 6 years & 36 & $18.95 \pm 2.90$ & $-0.33(-1.39$ to 0.72$)$ & 3 & 8.3 & $0.46(0.82-1.51)$ \\
\hline Yes - 1-2 years & 7 & $19.71 \pm 4.03$ & $0.40(-1.98$ to 2.78$)$ & 1 & 14.3 & $0.52(0.11-8.14)$ \\
\hline Yes - 3-4 years & 14 & $18.94 \pm 3.11$ & $-0.32(-2.00$ to 1.37$)$ & 1 & 7.1 & $0.38(0.05-2.97)$ \\
\hline Yes - 5-6 years & 15 & $18.60 \pm 2.14$ & $-0.75(-2.32$ to 0.94$)$ & 1 & 6.7 & $0.35(0.05-2.67)$ \\
\hline
\end{tabular}

${ }^{*}$ GLM regression, adjusted for gender, birth year (calendar year), gestational age, birth weight, and maternal characteristic (age, education, income, marital status).

${ }^{\dagger}$ Logistic regression, adjusted for gender, birth year (calendar year), gestational age, birth weight, and maternal characteristic (age, education, income, marital status).

Table 5. Change in BMI (95\% CI) between the exposed and the unexposed according to type of deceased relative and timing of exposure: hierarchical linear model*

\begin{tabular}{|c|c|c|c|c|}
\hline Death of a relative & All 0-6 years & $0-2$ years & $3-4$ years & $5-6$ years \\
\hline \multicolumn{5}{|l|}{ Parent } \\
\hline Number exposed & 157 & 33 & 50 & 74 \\
\hline Number unexposed & 12,911 & 12,911 & 12,911 & 12,911 \\
\hline Difference in BMI & $-0.01(-0.40$ to 0.38$)$ & $0.35(-0.50$ to 1.19$)$ & $0.10(-0.59$ to 0.79$)$ & $-0.27(-0.84$ to 0.29$)$ \\
\hline$P$ value & 0.96 & 0.41 & 0.78 & 0.74 \\
\hline \multicolumn{5}{|l|}{ Mother } \\
\hline Number exposed & 42 & 8 & 18 & 16 \\
\hline Number unexposed & 13,026 & 13,026 & 13,026 & 13,026 \\
\hline Difference in BMI & $0.35(-0.40$ to 1.10$)$ & $0.63(-1.08$ to 2.35$)$ & $0.34(-0.81$ to 1.49$)$ & $0.16(-1.06$ to 1.37$)$ \\
\hline$P$ value & 0.35 & 0.41 & 0.78 & 0.74 \\
\hline \multicolumn{5}{|l|}{ Father } \\
\hline Number exposed & 116 & 25 & 33 & 58 \\
\hline Number unexposed & 12,952 & 12,952 & 12,952 & 12,952 \\
\hline Difference in BMI & $0.15(-0.60$ to 0.31$)$ & $0.26(-0.71$ to 1.23$)$ & $0.05(-0.89$ to 0.80$)$ & $-0.40(-1.04$ to 0.24$)$ \\
\hline P value & 0.53 & 0.60 & 0.92 & 0.23 \\
\hline
\end{tabular}

*Adjusted for gender, birth year (calendaryear), gestational age, birth weight, and maternal characteristic (age, education, income, marital status). The unexposed as reference group. 
Li et al.: Bereavement in Early Life and Later Childhood Overweight

\section{Discussion}

In this cohort study, we observed that children who were bereaved by the death of a parent during the first 6 years of life had similar BMI value, similar prevalence of overweight or similar risk of overweight at 7-13 years of age, compared with those who were not exposed. The results were consistent across exposure strata by timing of exposure, relation of the child to the deceased relative, and cause of death.

Early stress in the form of maternal food insecurity in monkeys can result in peripubertal emergence of obesity [11]. Several studies in humans showed that maternal postpartum distress can lead to childhood overweight, but the retrospective collection of exposure data causes concerns about the validity of data [18-20]. Later and larger population-based studies of postpartum distress and depression did not indicate such effects $[32,33]$. Findings in our study further suggest that stress following bereavement at a very early age might not be a strong independent risk factor of childhood overweight.

The observed similar risk between the exposed and the unexposed may be explained by several mechanisms. Firstly, an infant or a young toddler may not perceive bereavement as stressful as adolescents or adults because his/her cognitive capacities have not matured enough [34-36]. Secondly, grief reactions abate over time for most bereaved children, although a minority of the children have long-term difficulties. [37, 38]. Thirdly, children's understanding of death and their coping mechanisms would be closely related to the agedependent developmental capacity $[16,39,40]$. To segregate children into developmentally more homogenous subgroups, for example by age group, might help to clarify whether different patterns of associations exist. However, the sample size in our study may be not sufficient enough, as illustrated by the wide confidence intervals of the estimates.

We have previously shown that exposure to maternal bereavement during the year before pregnancy was associated with an increased risk of overweight in offspring in early adolescence but not at 7-9 years of age [41]. We excluded individuals exposed to prenatal bereavement in the present study with the assumption that this exposure occurs independently of postnatal bereavement, as the size of the respective exposed groups did not allow a valid combined analysis. The lack of association with postnatal bereavement suggests that the previously demonstrated association with prenatal bereavement is not based on carryover effects from the prenatal bereavement to the postnatal period.

However, our findings cannot rule out the possibility that early postnatal stress may contribute to an increased predisposition of overweight in late childhood or adulthood [1214]. A few children do develop mood and physiological difficulties [38]. Bereavement during the early postnatal period potentially leads to stress in mothers or other family members, whose negative mood or changed behaviors may affect the infant's behavioral or psychological state for at least some children. Evidence from human studies has shown that psychological stress during late childhood, possibly involving emotional deprivation and parental neglect, may increase the risk of obesity in adulthood [42]. As mentioned previously, the effect of prenatal stress following bereavement cannot be observed until early puberty period; thus it could be possible that the effect following stress at an early age may become manifest after many years of follow-up, which can be confirmed by further studies.

The strengths of our study are its population-based longitudinal design, the objective measurement of exposure, a large exposure contrast, and the high-quality data on endpoints that are recorded independently of the exposure status. The CSHRR is a unique data source for obesity research with detailed data on growth with a high validity [26]. In particular, endpoint data from multiple time points reduce the possibility of a chance finding. Our study included virtually all school children in the Copenhagen municipality area, and selection bias is unlikely. 
One of the limitations in the study is that children were not interviewed at any time point in order to determine the characteristics of their bereavement experience, which might represent different pathways from exposure to outcomes in either a negative developmental direction or positive developmental direction.[38] Secondly, we lack information on quality of the relationship to the lost parent, as it is more stressful to loss a parent with whom a child has the primary attachment than loss of an absent parent $[43,44]$ Thirdly, we lack the information on children's diet or nutrition, physical activities as well as other possibly mediating factors on the pathway to overweight or obesity. Lastly, the relatively modest size of the exposed cohort did not permit us to further categorize the exposure according to nature of the bereavement, such as cause of death [45].

We conclude that this study did not support that stress exposure following bereavement during the first 6 years of life influences the development of overweight in later childhood. However, it does not exclude a long-term effect or an effect of other type of stress exposure.

\section{Acknowledgement}

The study was supported by agrant from European Research Council ((EU 7th Framework Programme (FP7), ERC-StG-2010 no.260242) to Dr. Jiong Li and by grants from Danish Medical Research Council (projects no. 271-05-0616, no. 271-07-0437, 09-072986), the Danish National Science Foundation, and NordForsk (070331). The study is part of the Danish Obesity Research Centre, DanORC (www.danorc.dk). We thank Dr. Chunsen Wu for his assistance on multiple imputations.

\section{Disclosure Statement}

Conflicts of interest: None declared.

\section{References}

1 International Obesity Taskforce: IOTF Demands Action on Childhood Obesity Crisis. www iotf org/media/ IOTFmay $12 \mathrm{htm}$.

2 Lobstein T, Baur L, Uauy R: Obesity in children and young people: a crisis in public health. Obes Rev 2004; 5(suppl 1):4-104.

3 Gluckman PD, Hanson MA, Beedle AS, Raubenheimer D: Fetal and neonatal pathways to obesity. Front Horm Res 2008;36:61-72.

4 Gluckman PD, Hanson MA, Cooper C, Thornburg KL: Effect of in utero and early-life conditions on adult health and disease. N Engl J Med 2008;359:61-73.

- 5 Hawkins SS, Law C: A review of risk factors for overweight in preschool children: a policy perspective. Int J Pediatr Obes 2006 2001;195-209.

6 Birch LL, Ventura AK: Preventing childhood obesity: what works? Int J Obes (Lond) 2009;33(suppl 1);S74S81.

- 7 Gillman MW, Rifas-Shiman SL, Camargo CA Jr, Berkey CS, Frazier AL, Rockett HRH, Field AE, Colditz GA: Risk of overweight among adolescents who were breastfed as infants. JAMA 2001;285:2461-2467.

8 Armstrong J, Reilly JJ: Breastfeeding and lowering the risk of childhood obesity. Lancet 2002;359:20032004.

9 Philipsen NM, Philipsen NC: Childhood overweight: prevention strategies for parents. J Perinat Educ 2008; 17:44-47.

10 Dubolis L, Girard M: Early determinants of overweight at 4.5 years in a population-based longitudinal study. Int J Obes (Lond) 2006;30:610-617.

11 Kaufman D, Banerji MA, Shorman I, Smith EL, Coplan JD, Rosenblum LA, Kral JG: Early-life stress and the development of obesity and insulin resistance in juvenile bonnet macaques. Diabetes 2007;56:1382-1386.

12 Barker D: Fetal origins of adult disease; in Polin RF, Fox WW, Abman SH, (eds): Fetal and Neonatal Physiology. Philadelphia, Saunders, 2004, pp 160-165. 
Li et al.: Bereavement in Early Life and Later Childhood Overweight

$>13$ modulation by newborn nutrition. Am J Physiol Regul Integr Comp Physiol 2005;288:R91-R96.

14 Vickers MH, Breier BH, Cutfield WS, Hofman PL, Gluckman PD: Fetal origins of hyperphagia, obesity, and hypertension and postnatal amplification by hypercaloric nutrition. Am J Physiol Endocrinol Metab 2000; 279:E83-E87.

15 Goodkin K, Baldewicz TT, Blaney NT, Asthana D, Kumar M, Shapshak P, Leeds B, Burkhalter JE, Rigg D, Tyll MD, Cohen J, Zheng WL: Physiological effects of bereavement and bereavement support group interventions; in Stroebe MS, Hansson RO, Stroebe W, Schut H, (eds): Handbook of Bereavement Research. Washington DC, American Psychological Association, 2001, pp 671-704.

16 Webb NB: Helping Bereaved Children, 2nd ed. New York, Guilford Press, 2002.

-17 D’Argenio A, Mazzi C, Pecchioli L, Di LG, Siracusano A, Troisi A: Early trauma and adult obesity: is psychological dysfunction the mediating mechanism? Physiol Behav 2009;98:543-546.

-18 Nader PR, O’Brien M, Houts R, Bradley R, Belsky J, Crosnoe R, Friedman S, Mei Z, Susman EJ, for the National Institute of Child Health and Human Development Early Child Care Research Network: Identifying risk for obesity in early childhood. Pediatrics 2006;118:e594-e601.

19 Stenhammar C, Olsson GM, Bahmanyar S, Hulting AL, Wettergren B, Edlund B, Montgomery SM: Family stress and BMI in young children. Acta Paediatr 2010;99:1205-1212.

-20 Surkan PJ, Kawachi I, Peterson KE: Childhood overweight and maternal depressive symptoms. J Epidemiol Commun Health 2008;62:e11.

21 Harrison L, Harrington R: Adolescents' bereavement experiences. Prevalence, association with depressive symptoms, and use of services. J Adolesc 2001;24:159-169.

$\checkmark 22$ Yamamoto K, Davis OL Jr, Dylak S, Whittaker J, Marsh C, van der Westhuizen PC: Across six nations: stressful events in the lives of children. Child Psychiatry Hum Dev 1996;26:139-150.

-23 Pedersen CB, Gotzsche H, Moller JO, Mortensen PB: The Danish Civil Registration System. A cohort of eight million persons. Dan Med Bull 2006;53:441-449.

-24 Knudsen LB, Olsen J: The Danish Medical Birth Registry. Dan Med Bull 1998;45:320-323.

25 Denmark Statistics: IDA - an Integrated Database for Labor Market Research (in Danish). 1991, www.dst. $d k$ / (under IDA (Intergrated Database for Arbejdsmarkedsforskning))

-26 Baker JL, Olsen LW, Andersen I, Pearson S, Hansen B, Sørensen TIA: Cohort Profile: The Copenhagen School Health Records Register. Int J Epidemiol 2009;38:656-662.

-27 Frank L: Epidemiology. When an entire country is a cohort. Science 2000;287:2398-2399.

-28 Mueller BR, Bale TL: Impact of prenatal stress on long term body weight is dependent on timing and maternal sensitivity. Physiol Behav 2006;88:605-614.

-29 Cole TJ, Bellizzi MC, Flegal KM, Dietz WH: Establishing a standard definition for child overweight and obesity worldwide: international survey. BMJ 2000;320:1240.

-30 White IR, Royston P, Wood AM: Multiple imputation using chained equations: issues and guidance for practice. Statist Med 2011;30:377-399.

$>31$ Sullivan LM, Dukes KA, Losina E: An introduction to hierarchical linear modelling. Statist Med 1999;18: 855-888.

32 Ajslev TA, Andersen CS, Ingstrup KG, Nohr EA, Sørensen TIA: Maternal postpartum distress and childhood overweight. PLos One 2010;5:e11136.

-33 Grote V, Vik T, von KR, Luque V, Socha J, Verduci E, Carlier C, Koletzko B: Maternal postnatal depression and child growth: a European cohort study. BMC Pediatr 2010;10;14.

34 Bowlby J: Attachment and Loss: Loss, Sadness and Depression. New York, Basic Books, 1980.

$>35$

$>36$

37 Christ GH: Impact of development on children's mourning. Cancer Pract 2000;8:72-81.

Wolfenstein M: How is mourning possible? Psychoanal Study Child 1966;21:93-123.

Blank NM, Werner-Lin A: Growing up with grief: revisiting the death of a parent over the life course. Omega (Westport ) 2011;63:271-290.

-38 Melhem NM, Porta G, Shamseddeen W, Walker Payne M, Brent DA: Grief in children and adolescents bereaved by sudden parental death. Arch Gen Psychiatry 2011;68:911-919.

39 Osterweis M, Solomon F, Green M: Bereavement: Reactions, Consequences, and Care. Washington DC, National Academy Press, 1984.

40 Stroebe MS, Stroebe W, Hansson RO, Schut H: Handbook of Bereavement Research: Consequences, Coping, and Care. Washington DC, American Psychological Association, 2001.

41 Li J, Olsen J, Vestergaard M, Obel C, Baker JL, Sørensen TIA: Prenatal stress exposure related to maternal bereavement and risk of childhood overweight. PLos One 2010;5:e11896.

-42 Lissau I, Sørensen TIA: Parental neglect during childhood and increased risk of obesity in young adulthood. Lancet 1994;343:324-327.

43 Stroebe MS, Stroebe W: Handbook of Bereavement. New York, Cambridge University Press, 1993.

-44 Bonanno GA, Kaltman S: Toward an integrative perspective on bereavement. Psychol Bull 1999;125:760776.

-45 Stroebe M, Schut H, Stroebe W: Health outcomes of bereavement. Lancet 2007;370:1960-1973. 